\title{
Chứng khoán hóa bất động sản: Lý luận và thực tiễn
}

\section{Real estate securitization: Theory and reality}

\author{
Nguyễn Kim Phước ${ }^{1 *}$ \\ ${ }^{1}$ Trường Đại học Mở Thành phố Hồ Chí Minh, Việt Nam \\ *Tác giả liên hệ, Email: phuoc.nk@ou.edu.vn
}

THÔNG TIN

DOI: 10.46223/HCMCOUJS.

proc.vi.16.1.1859.2021

Ngày nhận: 7/3/2021

Ngày nhận lại: 31/3/2021

Duyệt đăng: 7/4/2021

Tù khóa:

chứng khoán, bất động sản

KeywordS:

Real Estate Securitization

(RES), real estate

\section{TÓM TĂT}

Bài viết tập trung vào phân tích hình thức tạo vốn khả thi cho các dự án bất động sản là chứng khoán hóa. Chứng khoán hóa bất động sản là một hướng tạo vốn khả thi, tuy nhiên trên thực tế nhiều năm qua ở Việt Nam, vốn huy động cho bất động sản thông qua hình thức này vẫn "ì ạch". Thông qua tổng hợp các mô hình chứng khoán hóa bất động sản đã được áp dụng trên thế giới, các kinh nghiệm các quốc gia đã phát triển hình thức huy động động này, nhất là ở các quốc gia phát triển, và thực trạng của Việt Nam, bài viết đề xuất một số khuyến nghị nhằm góp phần thúc đẩy tính khả thi của hình thức huy động nguồn vốn đủ lớn cho lĩnh vực bất động sản ở Việt Nam trong thời gian tới.

ABSTRACT
The article focuses on analyzing the form of creating viable
capital for real estate projects, securitization. Real estate
securitization is a viable capital generation direction, but for many
years in Vietnam, capital mobilized for real estate through this form
has been "sluggish." Researching and synthesizing real estate
securitization models applied in the world, experiences of countries
that have developed this form of mobilization, and the current
situation of Vietnam. The article proposes some recommendations
to promote the feasibility of mobilizing a large enough capital
source for the real estate sector in Vietnam in the coming time.

\section{Giới thiệu}

Kể từ sau khủng hoảng kinh tế toàn cầu bắt đầu từ "bong bóng bất động sản ở Mỹ”, các Tổ Chức Tín Dụng (TCTD) ngày càng thắt chặt hơn hoạt động cho vay Bất Động Sản (BĐS). Năm 2019, Ngân Hàng Nhà nước (NHNN) ban hành thông tư 22 (hiệu lực vào ngày 01/01/2020) lại tiếp tục siết chặt hoạt động cho vay $\mathrm{B} Đ S$ bằng cách giảm dần tỷ lệ tối đa sử dụng vốn ngắn hạn cho vay trung và dài hạn (tỷ lệ hiện nay là $40 \%$ và xu hướng giảm dần xuống còn $30 \%$ ). Đồng thời, các khoản vay kinh doanh $\mathrm{BĐS}$ tăng hệ số rủi ro lên từ $150 \%-200 \%$. Điều này là do NHNN đang xếp hạng tín dụng BĐS thuộc nhóm tín dụng tiêu dùng có đặc thù rủi ro cao, khoản vay dài hạn và không tạo ra thu nhập.

Theo Thống đốc NHNN Lê Minh Hưng, tín dụng đối với lĩnh vực BĐS tăng 1,23\% so với cuối 2019 và chiếm 19,31\% tổng dư nợ tín dụng (đến cuối tháng 3/2020), trong đó có 62,43\% tổng dư nợ cho vay bất động sản đáp ứng cho nhu cầu nhà ở. Như vậy, vốn tín dụng vẫn chảy vào BĐS 
ở các phân khúc nhà ở bình dân (các phân khúc nhà ở cao cấp, BĐS du lịch nghỉ dưỡng bị hạn chế).

Ở Việt Nam, vốn đầu tư vào thị trường BĐS gồm 5 nguồn: Vốn của doanh nghiệp (DN) hoạt động kinh doanh BĐS trong nước, vốn FDI, huy động nguồn vốn từ các nhà đầu tư trực tiếp thông qua hình thức mua bán BĐS hình thành ở tương lai, nguồn vốn từ các TCTD (chủ yếu là từ các NHTM) và vốn huy động từ thị trường chứng khoán (TTCK), trong đó, vốn tín dụng chiếm khoảng 70\% (Hoang, 2016). Như vậy, nếu nguồn vốn tín dụng từ các TCTD ngày càng thắt chặt cho vay BĐS thì các DN BĐS đã khó khăn lại càng khó khăn hơn, bài toán về huy động vốn cho BĐS ngày càng khó giải hơn.

Theo Hiệp hội BĐS Tp.Hồ Chí Minh (HoRea), ngoài nguồn vốn huy động từ khách hàng và khoản vay từ ngân hàng, các nguồn vốn đáp ứng cho nhu cầu phát triển kinh tế nói chung và nhu cầu phát triển trên thị trường BĐS nói riêng vẫn còn đang thiếu. Trong khi đó, ở các quốc gia khác, các quỹ đầu tư, quỹ tín thác BĐS, quỹ tiết kiệm nhà ở, vốn từ CKH BĐS,... đã phát triển khá mạnh và trở thành nguồn cung vốn cho nền kinh tế khá hiệu quả (Thuy Linh, 2019).

Các TCTD (đặc biệt là các NHTM) siết chặt cho vay BĐS nên các DN BĐS tìm nguồn vốn khác bằng việc phát hành trái phiếu để huy động vốn. Tính riêng 7 tháng đầu năm 2019, trên sàn giao dịch HNX, giá trị phát hành trái phiếu DN lên đến 179.500 tỷ đồng (các $\mathrm{DN}$ BĐS là 6.993,9 tỷ đồng, chiếm tỷ trọng 35,07\%), với kỳ hạn phát hành bình quân 3,97 năm. Lãi suất các trái phiếu phát hành cao gấp 3 lần so với tiền gửi tiết kiệm có kỳ hạn 1 năm (lãi suất dao động từ $10-13 \% /$ năm). Chính vì lãi suất trái phiếu cao nên các NHTM thực hiện mua vào trái phiếu của các DN BĐS, điều này giống như một hình thức "đảo nợ khoản vay", "cơ cấu lại nợ” hoặc vay nợ với mức lãi suất khá cao. Chính vì lo ngại tình trạng này nên NHNN đang dự thảo thông tư qui định về đầu tư trái phiếu DN của các NHTM (trong dự thảo qui định, các TCTD không được mua trái phiếu DN nếu có tỷ lệ nợ xấu trên $3 \%$ ).

Thị trường $\mathrm{BĐS}$ khó có thể phát triển lành mạnh và bền vững nếu chỉ dựa vào vốn tín dụng từ các TCTD. Đồng thời, nếu trong thời gian tới, NHNN ban hành thông tư qui định về đầu tư trái phiếu $\mathrm{DN}$ và đưa vào áp dụng, thì các $\mathrm{DN} B Đ S$ cần phải tìm ra hình thức huy động vốn hiệu quả hơn mới có thể đảm bảo sự tồn tại và phát triển (vì vốn của $\mathrm{DN}$ hoạt động kinh doanh $\mathrm{BĐS}$ trong nước không đủ để đáp ứng nhu cầu, vốn FDI khó khả thi, vốn huy động từ các nhà đầu tư trực tiếp thông qua hình thức mua bán $\mathrm{BĐS}$ hình thành trong tương lai thì đang khó khăn, do tình hình kinh tế suy giảm và những rào cản pháp lý). Do đó, vốn huy động từ TTCK là một kênh huy động có thể giải quyết nhu cầu vốn cho DN BĐS.

Chứng khoán hóa $\mathrm{BĐS}$ là một hình thức huy động vốn khả thi đảm bảo cung ứng vốn cho phát triển thị trường $\mathrm{BĐS}$ ở Việt Nam. Tuy nhiên, nhiều năm qua, hình thức huy động vốn này cũng chưa thể phát triển do có những rào cản, những hạn chế về mặt thị trường và cơ chế chính sách. Do đó, nghiên cứu hoạt động huy động vốn cho lĩnh vực BĐS là điều cần thiết. Bài viết sử dụng phương pháp tổng hợp dữ liệu, phân tích dữ liệu và các thông tin thứ cấp từ các dữ liệu quốc gia, các tổ chức phân tích tài chính, các công trình nghiên cứu trong và ngoài nước để xây dựng căn cứ khoa học cho việc đưa ra các khuyến nghị nhằm tạo các điều kiện thuận lợi phát triển hình thức huy động vốn mới - $\mathrm{CKH}$ BĐS, góp phần tạo thêm kênh huy động vốn mới hữu hiệu hơn cho thị trường $\mathrm{BĐS}$ của Việt Nam trong tương lai.

\section{Cơ sở lý luận}

\subsection{Các khái niệm}

Theo OECD (1995), Chứng khoán hóa $(\mathrm{CKH})$ là việc phát hành các chứng khoán có tính "khả mại” được đảm bảo bằng các tài sản đặc biệt của chủ thể phát hành. Như vậy, CKH bất động 
sản là việc phát hành các chứng khoán có tính "khả mại - dễ mua bán hay tính thanh khoản cao" được đảm bảo bằng các tài sản là bất động sản của các chủ thể phát hành. $\mathrm{CKH}$ là việc đưa các tài sản (bất động sản) từ thị trường thế chấp sang thị trường chứng khoán (thị trường thứ cấp) - nơi có thể giao dịch, mua bán trao đổi, điều này giúp gia tăng tính thanh khoản của tài sản (Barmat, 1990).

CKH Bất Động Sản (BĐS) là một loại chứng khoán đặc biệt kết hợp giữa hình thức đầu tư chứng khoán và đầu tư $\mathrm{B} Đ S$, được đảm bảo bằng giá trị $\mathrm{BĐS}$ mà nó đại diện đồng thời cho phép nhà đầu tư kiếm lời trên giá $\mathrm{BĐS}$ này nhưng không nhất thiết phải nắm giữ quyền sở hữu trực tiếp (một phần hoặc toàn bộ) BĐS đó trong suốt quá trình sở hữu chứng khoán (Le, Huynh, \& Huynh, 2014).

CKH bất động sản là quá trình qui đổi giá trị BĐS (các dự án BĐS) sang hình thức cổ phiếu hay trái phiếu và đưa vào niêm yết trên sàn giao dịch chứng khoán nhằm huy động vốn cho các dự án $\mathrm{BĐS}$. Điều này giúp cho chủ đầu tư có vốn để đầu tư dự án, giúp cho những nhà đầu tư mua bán chứng khoán đảm bảo tính thanh khoản cao khi có nhu cầu chuyển nhượng và khắc phục những hạn chế của hình thức mua bán $\mathrm{BĐS}$ hiện nay (mua bán $\mathrm{BĐS}$ hình thành trong tương lai qua hình thức hợp đồng góp vốn).

\subsection{Các mô hình chứng khoán hóa BĐS}

Theo Theurillat và Crevoisier (2012, 2013), thị trường tín dụng BĐS được cấu thành gồm trị trường sơ cấp và thứ cấp. Trong thị trường sơ cấp, chủ thể vay nợ có yêu cầu và và thế chấp BĐS để vay nợ từ các tổ chức tín dụng (TCTD). Giá trị của khoản vay được các TCTD đưa ra dựa vào giá trị của tài sản đảm bảo (các $B Đ S$ ) và tính pháp lý của $B Đ S$. Các TCTD tập hợp các tài sản đảm bảo thành nhóm TSĐB $(\mathrm{BĐS})$ và sử dụng chúng để phát hành các trái phiếu. Như vậy, tài sản thế chấp (BĐS) đã được $\mathrm{CKH}$ qua hình thức trái phiếu (giao dịch hợp pháp trên thị trường thứ cấp). Điều này giúp các TCTD có thêm nguồn vốn tín dụng để cung ứng cho nền kinh tế.

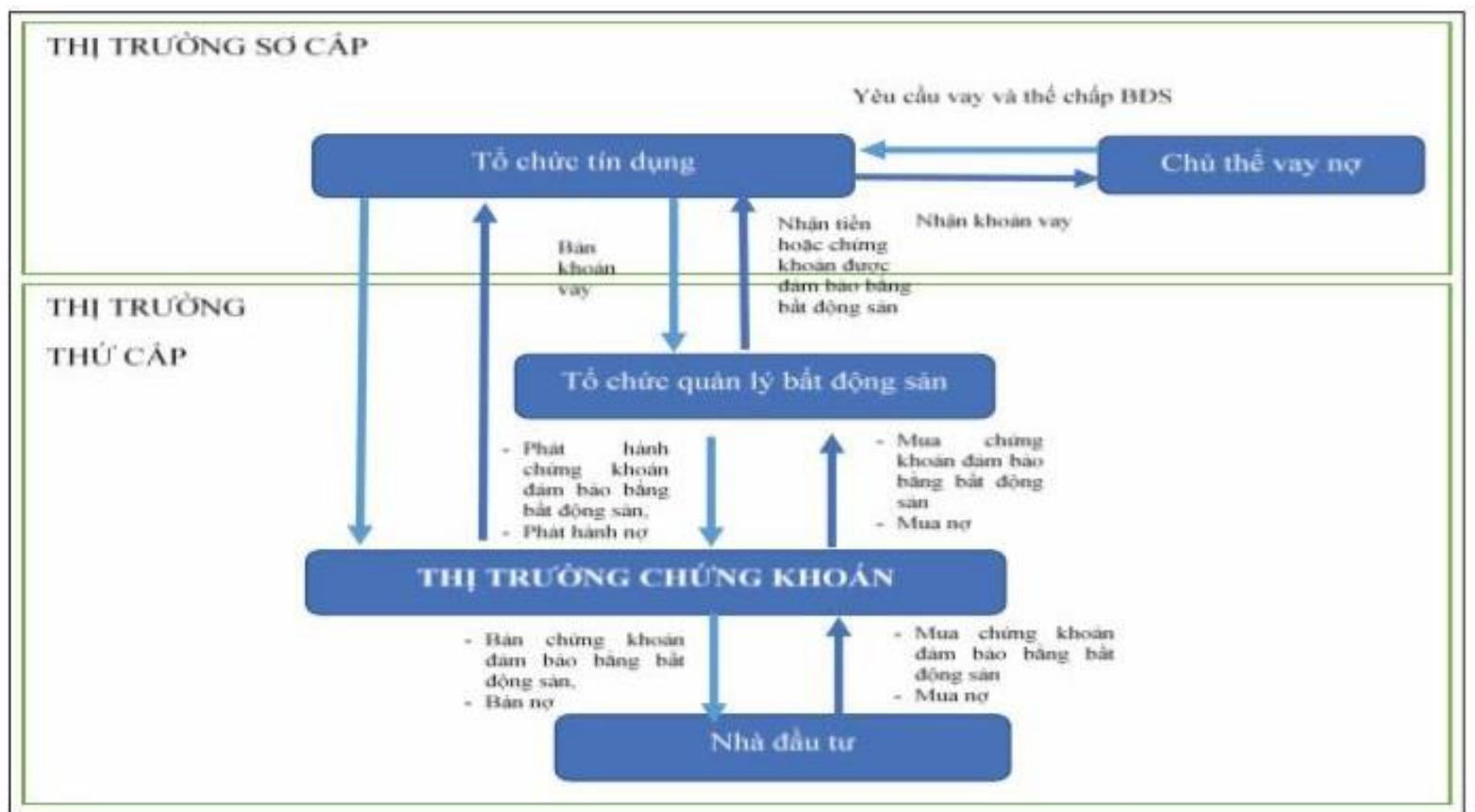

Hình 1. Cơ chế vận hành thị trường tín dụng $\mathrm{BĐS}$

Nguồn: Theurillat và Crevoisier (2012, 2013)

Theo Caselli và Gatti (2005), các Tài Sản Tài Chính (TSTC) được hình thành từ các khoản phải thu. Trái phiếu được ngân hàng hay các TCTD tạo ra từ khoản phải thu này, sau đó bán cho 
các nhà đầu tư để thu về các khoản nợ. Các nhà đầu tư (người mua trái phiếu) trở thành chủ nợ mới và họ có quyền đòi lại số tiền đã đầu tư (cả gốc và lãi) khi đến hạn. Như vậy, CKH BĐS thực chất là các khoản vay được thế chấp bằng $\mathrm{BĐS}$ được hình thành từ việc chuyển đổi các tài sản thế chấp là $\mathrm{BĐS}$ qui đổi thành giá trị trái phiếu (người cho vay thành người mua trái phiếu). Người đi vay (tổ chức phát hành - chủ nợ) chuyển toàn bộ giấy tờ có liên quan đến $\mathrm{BĐS}$ đó cho nhà đầu tư (người mua trái phiếu). Loại trái phiếu này có độ an toàn cao nhưng lãi suất thường thấp hơn so với các chứng khoán có đảm bảo bằng TSTC khác. Thực chất đây là thương vụ bán tài sản. Lúc này, người bán không phải chịu rủi ro thua lỗ từ $\mathrm{BĐS}$ và sự biến động giá $\mathrm{BĐS}$ trên thị trường. Tuy nhiên, người mua cũng có những rủi ro nhất định, nhất là rủi ro có liên quan đến vấn đề pháp lý của BĐS đó.

Vì thế, ở các quốc gia có hoạt động CKH BĐS phát triển, việc khởi tạo CKH BĐS ban đầu thường do các TCTD (hay ngân hàng) thực hiện, sau đó bán lại cho một SPV (Special porpose vehicle - tổ chức tài chính phục vụ mục đích đặc biệt) nhằm hạn chế rủi ro, SPV chuyển hóa tài sản (BĐS) đó thành chứng khoán, phát hành và đưa vào chuyển nhượng tư do trên thị trường vốn (TTCK).

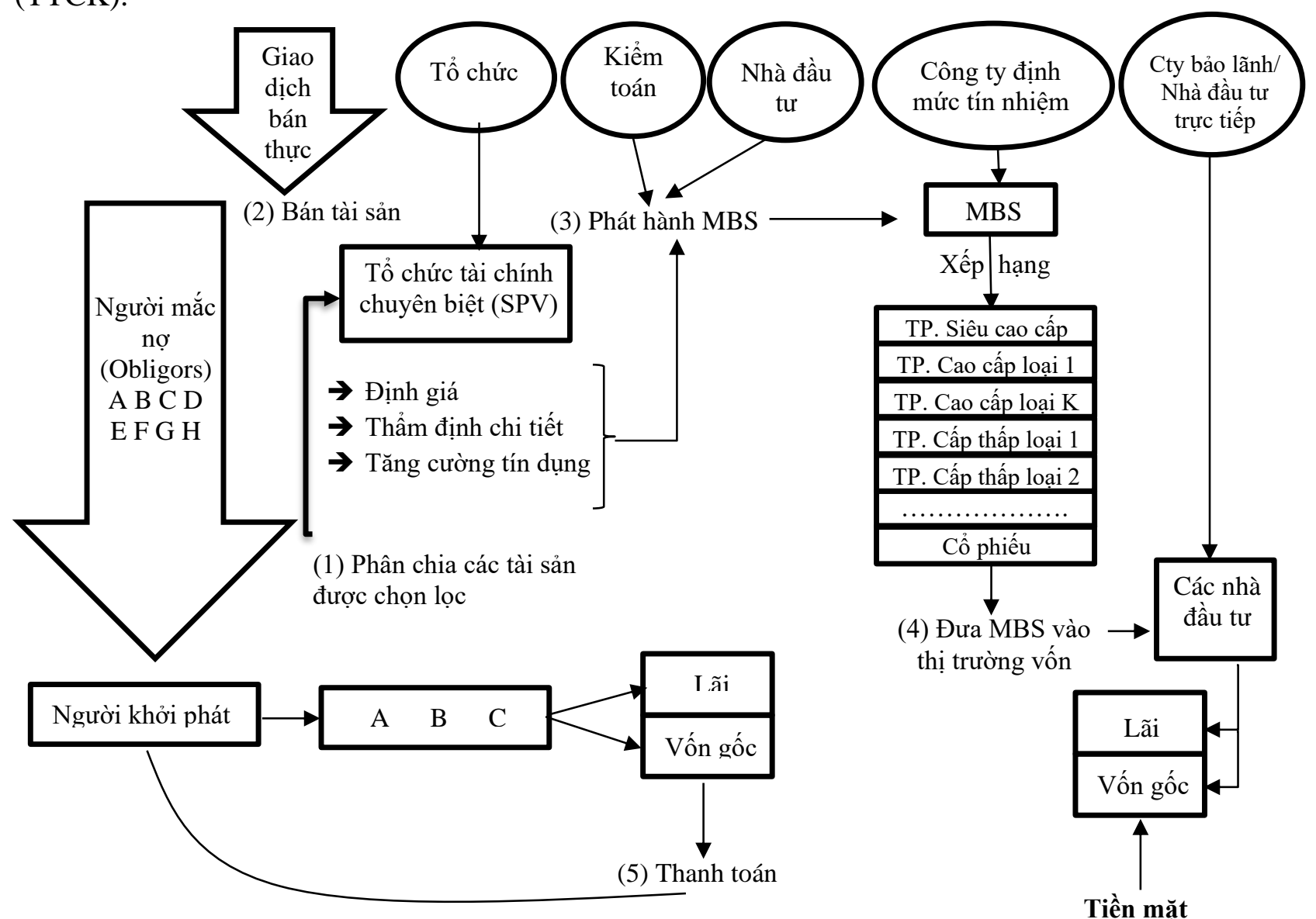

Hình 2. Cơ chế huy động vốn thông qua CKH các khoản vay

Nguồn: Caselli và Gatti (2005) 


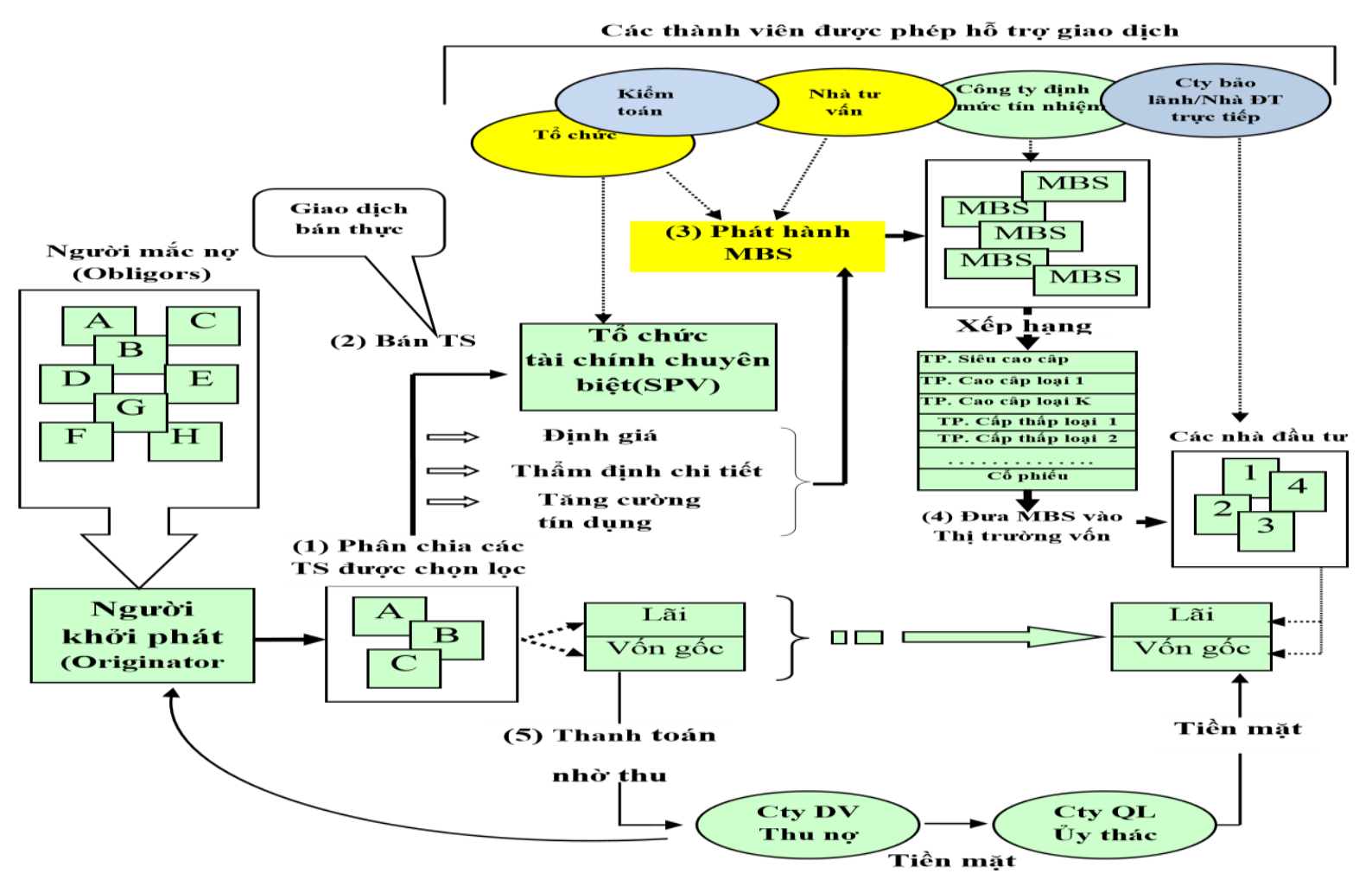

Hình 3. Mô hình chứng khoán hóa BĐS

Nguồn: Le, Huynh, và Huynh (2014)

Le và cộng sự (2014) dựa vào mô hình của Caselli và Gatti (2005)và nghiên cứu tình hình thực tế của Việt Nam đã đề xuất thêm 2 tổ chức tham gia trong mô hình CKH BĐS là công ty dịch vụ thu nợ và công ty quản lý ủy thác. Đồng thời, nhóm nghiên cứu cũng đã đưa các nhà tư vấn, kiểm toán, công ty định mức tín nhiệm, công ty bảo lãnh hay nhà đầu tư trực tiếp thành nhóm "các thành viên được hỗ trợ giao dịch". Các điểm còn lại trong mô hình của Le và cộng sự (2014) giống như mô hình của Caselli và Gatti (2005).

Le và cộng sự (2014) thực hiện khảo sát đối tượng là nhà đầu tư, các nhân sự đang làm việc tại tại công ty chứng khoán, công ty $\mathrm{BĐS}$, nhằm thu thập ý kiến (nhận định) của họ về các vấn đề có liên quan $\mathrm{BĐS}$, chứng khoán hóa $\mathrm{BĐS}$. Phương pháp thống kê, so sánh, tổng hợp được nhóm nghiên cứu sử dụng nhằm đánh giá tình hình biến động của tín dụng $\mathrm{BĐS}$ tại Việt Nam lúc bấy giờ. Đồng thời, nhóm nghiên cứu còn thực hiện tham khảo kinh nghiệm chứng khoán hóa BĐS của một số nước trên thế giới, nhằm đề xuất mô hình chứng khoán hóa (Hình 2). Tuy nhiên từ đó đến nay, $\mathrm{CKH} B Đ S$ ở Việt Nam cũng chưa phát triển và mô hình này cũng chưa được phát huy trong thực tiễn. 


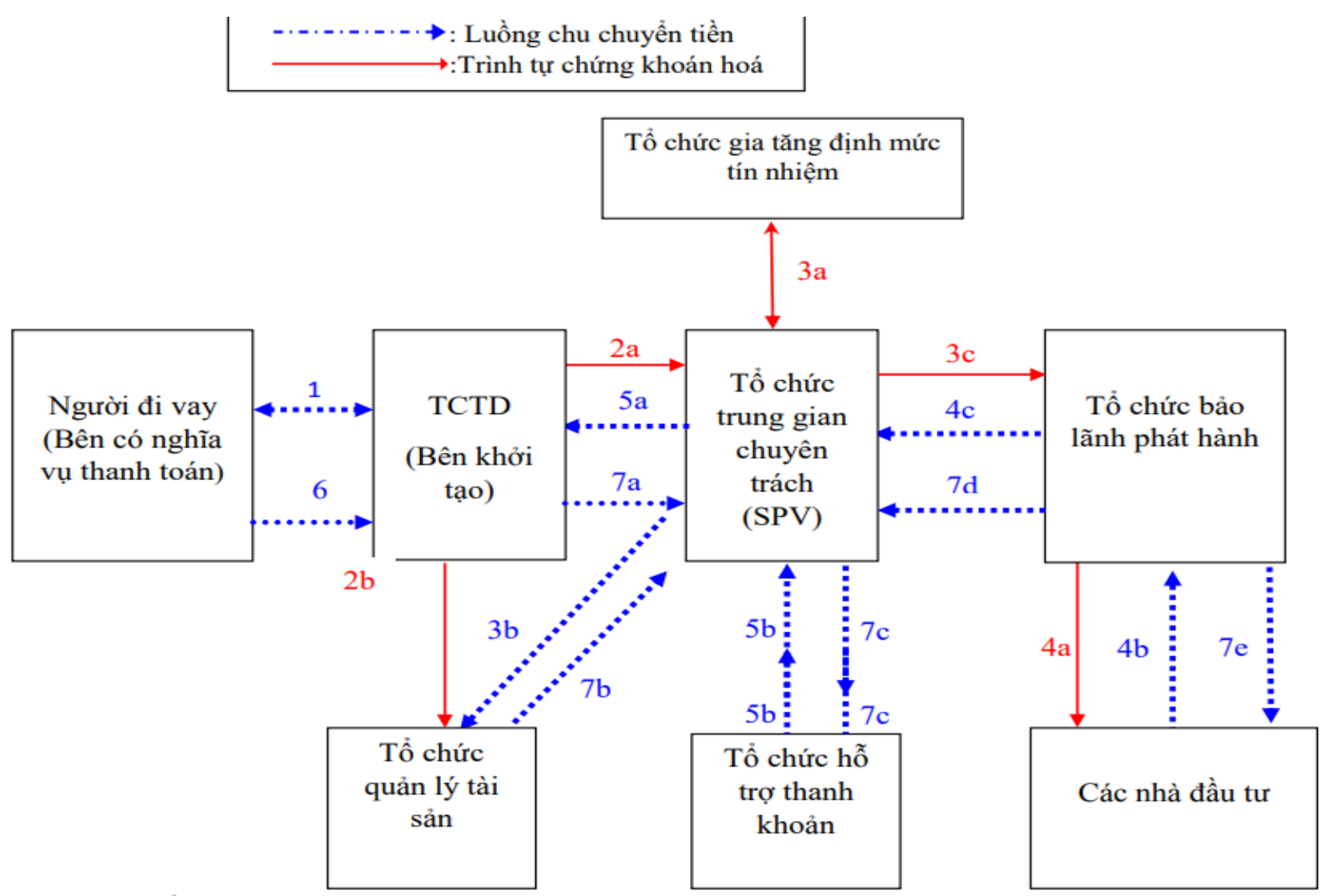

Hình 4. Qui trình phát hành chứng khoán ra công chúng

Nguồn: Davidson, Sanders, Wolff, và Ching (2003)

So với mô hình của Caselli và Gatti (2005), mô hình của Davidson và cộng sự (2003) đơn giản hơn, cụ thể là người đi vay (chủ dự án BĐS hay người có $\mathrm{BĐS}$ ) thực hiện vay vốn với các TCTD (bên khởi tạo), TCTD liên hệ SPV, SPV liên hệ tổ chức gia tăng định mức tín nhiệm để xác định mức tín nhiệm, sau khi định mức tín nhiệm, SPV liên hệ tổ chức bảo lãnh phát hành để thực hiện phát hành ra công chúng (các nhà đầu tư). Để hỗ trợ trong quá trình phát hành và sau khi phát hành, các SPV cần có các tổ chức quản lý tài sản và hỗ trợ thanh khoản. Mô hình này khá đơn giản và tách biệt khâu định giá ra khỏi các SPV nên đảm bảo tính chính xác và minh bạch hơn. Tuy nhiên, mô hình này cũng có hạn chế là chưa có sự tham gia nhiều của các quỹ đầu tư ủy thác, chưa chặt chẽ trong khâu thu hồi vốn gốc và lãi. Điều này hạn chế đối tượng đầu tư và tiềm ẩn các rủi ro nhất định cho nhà đầu tư.

\section{Phương pháp nghiên cứu}

Đề tài nghiên cứu sử dụng phương pháp nghiên cứu định tính. Dữ liệu và thông tin thứ cấp được sử dụng để phân tích, làm rõ vấn đề nghiên cứu. Đặc biệt, đề tài sử dụng các mô hình chứng khoán hóa $\mathrm{BĐS}$ đã được một số quốc gia áp dụng, mô hình của các nhà nghiên cứu đề xuất ứng dụng vào Việt Nam trước đây. Đồng thời, đề tài cũng nghiên cứu kinh nghiệm của các quốc gia có hoạt động chứng khoán hóa BĐS thành công và đặc điểm tình hình thực tế của Việt Nam để xây dựng căn cứ khoa học cho việc đề xuất các giải pháp huy động nguồn vốn vào thị trường $\mathrm{BĐS}$ thông qua hình thức chứng khoán hóa.

\section{Kết quả nghiên cứu}

\subsection{Kinh nghiệm của các quốc gia ứng dụng mô hình chứng khoán hóa BĐS}

CKH tài sản nợ bắt đầu ở Mỹ vào những năm 1948 - 1968 sau đó nhanh chóng phổ biến ở 
Malaysia (1986), Pháp (1988), Hong Kong (1997) Nhật và Hàn Quốc (1998). Nhiều quốc gia đã ứng dụng thành công $\mathrm{CKH}$ các khoản nợ. Tại các quốc gia này, các công ty chứng khoán hóa (SPV) đã được thành lập và hoạt động khá hiệu quả (ví dụ: Fannie Mae và Freddie Mac ở Mỹ; công ty quản lý nợ và khai thác tài sản tại các NHTM (AMC) ở Trung Quốc, Malaysia,...). Các $\mathrm{AMC}$ ở các quốc gia này không đơn thuần chỉ là mua bán các khoản nợ như VAMC ở Việt Nam (các VAMC ở Việt Nam chỉ để giải quyết nợ xấu). Các AMC ở các nước có vai trò lớn hơn, là nơi thu hút nguồn vốn nhàn rỗi trong dân để đầu tư vào $\mathrm{BĐS}$.

Zhang và Fund (2006, theo Gambro \& Leichtner, 1997) nghiên cứu tại thị trường Trung Quốc, Hàn Quốc, Singapore, Nhật Bản và Đài Loan giai đoạn (1997- 2006) cho thấy, tăng trưởng của thị trường $\mathrm{BĐS}$ và tăng trưởng kinh tế luôn nghịch chiều với nhau, thị trường $\mathrm{BDS}$ tăng trưởng nóng là một trong các nguyên nhân chính dẫn đến tình trạng đóng băng của TTCK. Tuy nhiên, Chang \& Chang (2014) nghiên cứu ở Trung Quốc đã rút ra kết luận rằng, khi thị trường BĐS tăng trưởng nóng thì chính phủ cần có cơ chế hỗ trợ lãi suất (thực hiện thông qua cơ chế chuyển tải giá trên TTCK) sẽ mang lại hiệu quả cao hơn. Như vậy, TTCK và thị trường BĐS luôn có mối quan hệ tác động qua lại mật thiết với nhau.

Tại Trung Quốc, CKH các TSTC (tài sản nợ) được thực hiện bởi các công ty quản lý nợ và khai thác tài sản $(\mathrm{AMC})$ và các $\mathrm{NHTM}$. Các $\mathrm{AMC}$ mua lại các khoản nợ được đảm bảo bằng tài sản tại các NHTM, sau đó chuyển đổi các khoản nợ thành cổ phần của $\mathrm{AMC}$ trong các $\mathrm{DN}$ đó (DN có tài sản đảm bảo đó). Khi đó, $\mathrm{AMC}$ tham gia vào các hoạt động quản lý, tái cấu trúc $\mathrm{DN}$ để đảm bảo $\mathrm{DN}$ hoạt động hiệu quả hơn, $\mathrm{AMC}$ thu hồi vốn từ việc bán cổ phần (cổ phần hình thành từ việc chuyển đổi các khoản nợ).

Ở Mỹ, mô hình mã hóa BĐS áp dụng công nghệ Blockchain và sử dụng mã Token (OTP) đang dần thay thế phương pháp đầu tư $\mathrm{BĐS}$ truyền thống. Đây là một mô hình đầu tư $\mathrm{BĐS}$ dưới dạng quỹ đầu tư tín thác. Theo đó mỗi OTP đại diện cho 1 phần giá trị của $\mathrm{B} Đ S$ và được giao dịch như cổ phiếu. Cổ phiếu đó được giao dịch như những mã cổ phiếu khác trên thị trường chứng khoán. Như vậy, các nhà đầu tư có tỷ lệ sở hữu BĐS tùy thuộc vào tỷ lệ sở hữu cổ phần theo OTP đã mua. Điều này giúp cho các công ty $\mathrm{BĐS}$ tiếp cận nguồn vốn và khách hàng dễ dàng, tạo tính thanh khoản cao cho các cổ phiếu BĐS. Nhà đầu tư (có dự án BĐS) có nguồn vốn để phát triển dự án và không phải lo lắng khoản nợ gốc và lãi vay phải trả cho các TCTD. Mô hình này được thực hiện nhờ sự kết hợp giữa công ty BĐS Bro Pele và công ty công nghệ Blockchain Fluidity. Tuy nhiên, CKH BĐS dạng này ở Mỹ chỉ dành cho những công ty có uy tín, đảm bảo tính minh bạch và thông suốt thông tin giữa người mua và người bán.

\subsection{Thục trạng chứng khoán hóa bất động sản tại Việt Nam}

Cách đây gần 15 năm, những dấu hiệu CKH BĐS đã được hình thành ở Việt Nam (ví dụ UBCKNN và Bộ Xây dựng khởi động đề án "CKH BĐS", chính phủ ban hành các Nghị định 52/2006, Nghị định 71/2010, thông tư 16/2010) nhằm tìm giải pháp cung ứng vốn cho thị trường BĐS của Việt Nam. Tuy nhiên, từ đó đến nay, hoạt động này vẫn đang "ì ạch" như lời nhận định của các chuyên gia trong lĩnh vực tài chính, BĐS. Theo các chuyên gia, điều này là do nhà đầu tư chưa "hào hứng" với sản phẩm này, họ chưa tìm thấy "sức hấp dẫn" của hàng hóa này, đồng thời cũng do cơ chế vận hành của hàng hóa này chưa được thể chế cụ thể, chưa có khung pháp lý hoàn chỉnh.

\section{Bảng 1}

Tình hình vay nợ của một số DN BĐS niêm yết 


\begin{tabular}{|l|r|r|r|r|r|}
\hline Doanh nghiệp & $\begin{array}{r}\text { Vốn chủ sở } \\
\text { hữu (VCSH) }\end{array}$ & Tổng vay nợ & $\begin{array}{c}\text { Hệ số } \\
\text { vay/VCSH }\end{array}$ & \multicolumn{1}{c|}{$\begin{array}{c}\text { Hàng tồn kho } \\
\text { (HTK) }\end{array}$} & $\begin{array}{c}\text { Tỷ lệ } \\
\text { HTK/VCSH }\end{array}$ \\
\hline Đất Xanh & 7.816 & 3.401 & $43,5 \%$ & 5.310 & $67,9 \%$ \\
\hline Khang Điền & 7.259 & 808 & $11,1 \%$ & 6.371 & $87,8 \%$ \\
\hline Nam Long & 5.765 & 927 & $16,1 \%$ & 4.700 & $81,5 \%$ \\
\hline TCH & 4.456 & 398 & $8,9 \%$ & 2.131 & $47,8 \%$ \\
\hline Phát Đạt & 3.892 & 1.869 & $48,0 \%$ & 7.016 & $180,3 \%$ \\
\hline DIG & 3.816 & 1.323 & $34,7 \%$ & 3.408 & $89,3 \%$ \\
\hline CEO Group & 3.478 & 1.968 & $56,6 \%$ & 1.626 & $46,8 \%$ \\
\hline Hà Đô & 3.223 & 5.106 & $158,4 \%$ & 3.394 & $105,3 \%$ \\
\hline Thủ Đức House & 2.472 & 1.008 & $40,8 \%$ & 1.167 & $47,2 \%$ \\
\hline
\end{tabular}

Nguồn: Truong (2019)

Theo tính toán của Truong (2019), một số DN BĐS (DN có niêm yết trên sàn chứng khoán) có hệ số vay nợ/vốn chủ sở hữu (VCSH) khá cao, cao nhất Hà Đô với mức vay nợ đến gần $160 \% / \mathrm{VCSH}$, tiếp theo đó là $\mathrm{CEO}$ Group, Đất Xanh, Phát Đạt (từ 56,6\% đến 43,5\%). Điều này là do hàng tồn kho (KTK) của các DN này khá cao (cao nhất là Phát Đạt, thứ 2 là Đất Xanh và thứ 3 là Khang Điền). Hàng hóa bán không được nên các $\mathrm{DN}$ này gặp khó khăn khi thu hồi vốn đầu tư và khả năng thanh khoản của các $\mathrm{BĐS}$ cũng thấp. Theo đó, các $\mathrm{DN}$ BĐS ngoài việc khó khăn về vốn đầu tư, vốn vay lại hạn chế, mà $B Đ S$ đầu tư thì tồn kho, do đó, nếu không có nguồn vốn hữu hiệu hơn, lĩnh vực BĐS khó có thể tồn tại và phát triển bền vững. 


\section{Bảng 2}

Top 20 DN BĐS có hàng tồn kho cao nhất 2019

Đvt: Tỷ đồng

\begin{tabular}{|c|c|c|c|}
\hline Mä & Näm 2018 & Näm 2019 & $(+/-\phi)$ \\
\hline VमM & $36,858.43$ & $60,296.85$ & 63.59 \\
\hline NVL & $32,826.04$ & $57,205.79$ & 74.27 \\
\hline $\mathrm{QCO}$ & 7.514 .81 & $8,500.32$ & 13.11 \\
\hline$P D R$ & $5,865.81$ & $7,994.80$ & 36.29 \\
\hline $\mathrm{KBC}$ & $8,592.83$ & $7,547.76$ & $(12.16)$ \\
\hline $\mathrm{KDH}$ & $5,817.38$ & $7,037.11$ & 20.97 \\
\hline$D \times G$ & $4,605.15$ & $6,791.46$ & 47.48 \\
\hline $1 . J \mathrm{C}$ & $5,110.42$ & $4,780.16$ & (6.46) \\
\hline $\mathbb{N L G}$ & $3,261.23$ & $4,298.12$ & 31.79 \\
\hline DIG & $3,132,72$ & $4,193.60$ & 33.86 \\
\hline ITA & $4,373.27$ & $4,186.17$ & $(4.28)$ \\
\hline$S C R$ & $3,975.98$ & $4,159.54$ & 4.62 \\
\hline NBB & 3,13341 & $4,038.05$ & 28.87 \\
\hline S.JS & $3,504.11$ & $3,568.42$ & 1.84 \\
\hline HDG & $3,834.71$ & $3,498.01$ & (8.78) \\
\hline TDC & $3,570.93$ & $3,487.43$ & $(2.34)$ \\
\hline $\mathrm{CKG}$ & $1,807.76$ & $2,709.51$ & 49.88 \\
\hline$\triangle G G$ & 52.90 & $2,611,32$ & $4,846.14$ \\
\hline HPX & $1,160.95$ & $2,160.19$ & 86.07 \\
\hline$\vee P \|$ & $2,135,54$ & $2,077.23$ & $(2.73)$ \\
\hline
\end{tabular}

Nguồn: Huyen Vu (2020)

Trong các $\mathrm{DN}$ BĐS, theo số liệu thống kê (Bảng 2) hiện có 20 ông lớn ngành $\mathrm{BĐS}$ nắm giữ hơn 201 ngàn tỷ đồng hàng tồn kho. Trong đó, giá trị hàng tồn kho tăng liên tục trong 2 năm (2018 và 2019) đứng đầu trong 20 "đại gia" BĐS là VHM (Vinhomes) và NVL (CTCP Tập đoàn Đầu tư Địa ốc No Va). Trong đó, NVL có tốc độ tăng hàng tồn kho cao hơn VHM. Đây là những Tập đoàn BĐS có nhiều dự án đầu tư ở Việt Nam hiện nay, nhưng hàng hóa sản xuất ra khó bán, tính thanh khoản thấp dẫn đến tình trạng thiếu vốn nghiêm trọng của các $\mathrm{DN}$ này nói riêng và các DN BĐS nói chung.

Tính đến ngày 31/12/2019, tổng nợ vay của các DN bất động sản đạt 237,198 tỷ đồng, tương ứng tăng $24 \%$ so với thời điểm đầu năm. Trong đó vay và nợ tài chính ngắn hạn đạt 82,726 tỷ đồng (tăng 44\%), nợ và vay tài chính dài hạn đạt 154,471 tỷ đồng (tăng 15\%).

Năm 2019, các DN bất động sản phải trả 13,689 tỷ đồng lãi vay, tăng hơn 34\% so với 2018. Đó là chưa kể con số lãi vay được vốn hóa vào dự án, đây là phần chi phí "vô hình" đem lại những rủi ro đáng kể nhưng không dễ nhận diện ở bối cảnh hiện tại. Với tình trạng vay nợ và hàng tồn kho nêu trên (Bảng 2 \& 3) và chính sách "siết chặt tín dụng BĐS" của NHNN hiện nay, ngành BĐS chịu tác động kép, đã khó khăn lại càng khó khăn hơn. Do đó, các DN trong ngành phải nhanh chóng tìm hướng đi mới, nguồn vốn mới, cách thức huy động vốn hiệu quả hơn để giải quyết bài toán về vốn cho chính bản thân DN mình.

\section{Bảng 3}

Top 20 DN BĐS niêm yết có dư nợ vay cao nhất 2019 
Đvt: Tỷ đồng

\begin{tabular}{|c|c|c|c|}
\hline Mã & $\begin{array}{l}\text { Vay và nợ thuê tài } \\
\text { chính ngắn hạn }\end{array}$ & $\begin{array}{l}\text { Vay và nợ thuê tài } \\
\text { chính dài hạn }\end{array}$ & $\begin{array}{l}\text { Tống vay và nợ } \\
\text { thuê tâi chính }\end{array}$ \\
\hline NVL & $8,444.64$ & $26,145.64$ & $34,590.28$ \\
\hline VHM & $18,162.35$ & $8,343.03$ & $26,505.38$ \\
\hline FLC & $3,169.60$ & $3,293.92$ & $6,463.52$ \\
\hline HDG & $1,183.43$ & $4,637.15$ & $5,820.58$ \\
\hline HUT & 65.51 & $5,534.77$ & $5,600.28$ \\
\hline $\mathrm{D} \times \mathrm{G}$ & $1,063.20$ & $3,336.53$ & $4,399.73$ \\
\hline VPI & $1,695.36$ & $2,566.58$ & $4,261.94$ \\
\hline VRE & 19.42 & $2,765.31$ & $2,784.72$ \\
\hline CEO & $1,069.70$ & $1,270.06$ & $2,339.76$ \\
\hline SCR & $1,338.28$ & 920.48 & $2,258.76$ \\
\hline PDR & $1,201.60$ & 970.30 & $2,171.90$ \\
\hline $\mathrm{HPX}$ & 868.95 & $1,142.70$ & $2,011.65$ \\
\hline $\mathrm{KBC}$ & 804.04 & $1,121.90$ & $1,925.93$ \\
\hline CKG & 899.19 & 533.03 & $1,432.22$ \\
\hline TDC & $1,097.69$ & 317.48 & $1,415.17$ \\
\hline DIG & 547.81 & 729.66 & $1,277.47$ \\
\hline $\mathrm{TDH}$ & 918.03 & 324.08 & $1,242.10$ \\
\hline AGG & 262.36 & 808.09 & $1,070.45$ \\
\hline $\mathrm{SZC}$ & 110.71 & 854.17 & 964.88 \\
\hline HDC & 430.44 & 481.84 & 912.27 \\
\hline
\end{tabular}

Nguồn: Huyen Vu (2020)

\section{Bảng 4}

Các DN có giá trị phát hành trên 2.000 tỷ đồng

\section{Tên công ty}

Ngành

Phân loại

Niêm yết

Chưa niêm yết

BIDV

Ngân hàng

Bất động sản

Thực phẩm, đồ uống Niêm yết

5.000

Công ty CP Tập đoàn Masan

Bất động sản

Chưa niêm yết

4.950

Công ty CP Đầu tư Hạ tầng Kỹ thuật TP.HCM

Vận tải

Niêm yết

2.770

Công ty $\mathrm{CP}$ Đầu tư và Phát triển Golf Bình Hải

Du lịch, khách sạn Chưa niêm yết

2.746

Công ty $\mathrm{CP}$ Phát triển Golf Thiên Đường

Du lịch, khách sạn Chưa niêm yết

2.681

Nguồn: Mirae Asset (2020)

Để có thêm nguồn vốn đáp ứng nhu cầu sản xuất kinh doanh, các DN BĐS thực hiện phát hành trái phiếu nhằm huy động vốn từ các nhà đầu tư trong và ngoài nước. Điển hình như năm 2019, Công ty Cổ phần Đầu tư Phát triển Bất Động Sản TNR HOLDINGS Việt Nam phát hành 5.347 tỷ đồng trái phiếu (nhưng chưa niêm yết). 


\section{Bảng 5}

Kỳ hạn trái phiếu phát hành các ngành

\begin{tabular}{|l|c|c|c|c|}
\hline \multicolumn{2}{|c}{ Giá trị phát hành } & Tỷnh trọng & $\begin{array}{c}\text { Kỳ hạn bình } \\
\text { quân (năm) }\end{array}$ & $\begin{array}{c}\text { Lãi suất bình } \\
\text { quân (\%) }\end{array}$ \\
\hline Bất động sản & 22.461 & $37,21 \%$ & 5,74 & $10,8 \%$ \\
\hline Ngân hàng & 13.799 & $22,86 \%$ & 4,86 & $7,1 \%$ \\
\hline Du lịch, khách sạn & 10.048 & $16,65 \%$ & 4,87 & $10,1 \%$ \\
\hline Thực phẩm, đồ uống & 5.500 & $9,11 \%$ & 2,93 & $9,4 \%$ \\
\hline Vận tải & 2.770 & $4,59 \%$ & 3,60 & $11,0 \%$ \\
\hline Hàng hóa chủ chốt & 2.750 & $4,56 \%$ & 2,13 & $10,7 \%$ \\
\hline Dịch vụ tài chính & 1.555 & $2,58 \%$ & 1,98 & $9,4 \%$ \\
\hline Tiện ích & 860 & $1,42 \%$ & 12,23 & $10,4 \%$ \\
\hline Hàng gia dụng & 300 & $0,50 \%$ & 1,00 & $11,0 \%$ \\
\hline Khác & 200 & $0,33 \%$ & 2,00 & $10,0 \%$ \\
\hline Vật liệu & 60 & $0,10 \%$ & 5,00 & $9,0 \%$ \\
\hline Bán lẻ & 41 & $0,07 \%$ & 1,00 & $8,0 \%$ \\
\hline Năng lượng & 17 & $0,03 \%$ & 1,00 & $0,0 \%$ \\
\hline Tổng cộng & $\mathbf{6 0 . 3 6 1}$ & $\mathbf{1 0 0 \%}$ & $\mathbf{4 , 8 3}$ & $\mathbf{9 , 7 0 \%}$ \\
\hline
\end{tabular}

Nguồn: Mirae Asset (2020)

Bên cạnh đó, lĩnh vực BĐS cũng phát hành trái phiếu với giá trị khá lớn (trên 22.000 tỷ đồng trong năm 2019) với kỳ hạn bình quân trên 5 năm ở mức lãi suất bình quân trên $10 \%$ nhằm huy động vốn đáp ứng nhu cầu sản xuất kinh doanh. Theo kết quả thống kê (Bảng 2), ngành BĐS là ngành có giá trị trái phiếu phát hành cao nhất và mức lãi suất thuộc nhóm cao (trên $10 \%)$. Trong khi đó, lãi suất vay vốn từ các TCTD cũng chỉ dao động từ $8-10 \% /$ năm. Tuy nhiên, do các TCTD thắt chặt cho vay $\mathrm{BĐS}$ nên các $\mathrm{DN}$ phải chủ động tìm nguồn vốn khác và chấp nhận mức chi phí vốn cao hơn.

Theo Dũ liệu của NHNN cũng cho thấy, dư nợ tính dụng BĐS luôn luôn tăng qua các năm (năm sau luôn cao hơn năm trước từ $1 \%$ đến $2 \%$ ) và khoản dư nợ này chiếm (bình quân) khoảng gần $20 \% /$ /ổng dư nợ tín dụng của toàn nền kinh tế. Trong đó, dư nợ tín dụng đáp ứng cho nhu cầu về nhà ở chiếm tỷ trọng khoảng 62,43\% dư nợ tín dụng BĐS. Hiện nay, thị trường $\mathrm{BĐS} \mathrm{đang} \mathrm{có}$ hơn $10.000 \mathrm{DN}$ hoạt động. Tỷ suất lợi nhuận gộp trung bình khá cao của ngành BĐS khá cao (khoảng $25 \%$ đến $30 \%$ - chỉ thống kê $95 \mathrm{DN}$ có niêm yết trên thị trường chứng khoán). Ngành này cũng giúp giải quyết công ăn việc làm cho hàng ngàn lao động trên cả nước. Lĩnh vực $\mathrm{BĐS}$ còn kéo theo đến nhiều ngành công nghiệp, ngành hỗ trợ khác như (vật liệu, điện, thiết kế, nội ngoại thất,...) Do đó, con số nợ 1,6 triệu tỷ đồng của ngành BĐS là con số lớn nhưng không phải là không có khả năng thu hồi vốn.

Như vậy, ngành BĐS nếu không nhanh chóng giải quyết bài toán về vốn theo hướng khác thì khó có thể phát triển trong tương lai. Hình thức $\mathrm{CKH}$ BĐS được xem như một hướng huy động vốn mới có tính khả thi cao, đáp ứng nhu cầu vốn cho các $\mathrm{DN}$ BĐS và phù hợp với chính sách 
“thắt chặt tín dụng BĐS” của NHNN hiện nay. Tuy nhiên, để thực hiện được điều này, ngành BĐS cần có những hành lang pháp lý phù hợp, có những tổ chức đủ nguồn lực (nhân lực và tài liệc) đứng ra thực hiện. Bên cạnh đó, các rủi ro phát sinh trong quá trình $\mathrm{CKH}$ BĐS cũng là một rào cản hạn chế quyết định đầu tư của các nhà đầu tư. Do đó, hành lang pháp lý cũng cần chi tiết, cụ thể và phù hợp thực tế để đảm bảo tính khả thi của hình thức huy động vốn này.

\section{Kết luận và đề xuất giải pháp}

\subsection{Kết luận}

Huy động nguồn lực tài chính để phát triển thị trường BĐS là một bài toán khó, và hiện nay càng khó hơn khi các TCTD thực hiện thắt chặt tín dụng BĐS theo qui định của NHNN. Bên cạnh đó, tình hình những dự án treo, dự án không thực hiện đúng tiến độ như cam kết với nhà đầu tư (người mua), dự án $\mathrm{BĐS}$ có tính pháp lý chưa đầy đủ và rõ ràng dẫn đến hình thức đầu tư vào BĐS theo hình thức góp vốn (tài sản hình thành trong tương lai) cũng giảm dần. Vì thế, CKH BĐS theo xu hướng của các nước trên thế giới là điều không thể không nghĩ đến. Tuy nhiên, để thực hiện được điều này, chúng ta cần phải thực hiện khá nhiều vấn đề có liên quan, cần có sự hỗ trợ, chung tay góp sức của các cơ quan chính quyền các cấp, khả năng các cơ quan, DN trong lĩnh vực $\mathrm{BĐS}$, tài chính và chứng khoán, niềm tin và sự hiểu biết của nhà đầu tư,...

\section{2. Đề xuất giải pháp cung ứng vốn cho thị trừ̀ng BĐS qua hình thức chúng khoán}

\section{hóa}

CKH BĐS có thể được xem như một giải pháp mới để huy động vốn cho BĐS. Tuy nhiên, hình thức huy động này có thể thành công hay không tùy thuộc vào mức độ tham gia, hỗ trợ và sự chủ động của Quốc Hội, Chính Phủ, các Bộ ngành trung ương, các TCTD, các DN BĐS và tất cả các nhà đầu tư trong và ngoài nước, cụ thể như:

(i) Các cơ quan trung ương (lập pháp và hành pháp) cần ban hành và nhanh chóng hoàn thiện khung pháp lý hỗ trợ quá trình $\mathrm{CKH} B Đ S$. Các hình thức huy động vốn nói chung và huy động vốn bằng hình thức CKH BĐS nói riêng không thể vận hành nếu không có khuôn khổ pháp lý cụ thể, rõ ràng. Quốc Hội, Chính phủ, Bộ Tài chính, UBCKNN và NHNH có vai trò quan trọng trong việc xây dựng cơ chế, chính sách, hành lang pháp lý liên quan đến thị trường $\mathrm{B} Đ S$, thị trường tài chính và các hình thức, nghiệp vụ huy động vốn đáp ứng nhu cầu sản xuất kinh doanh của $\mathrm{DN}$ trong đó có DN BĐS - một lĩnh vực kinh doanh "thâm dụng vốn" trong nền kinh tế. Để CKH BĐS khả thi, các cơ quan có thẩm quyền cần ban hành các qui định cụ thể về thủ tục, quyền hạn và trách nhiệm của các bên liên quan trong quá trình tham gia mua bán $\mathrm{CKH}$ BĐS, trong đó cần nghiên cứu bổ sung các chủ thể có thể tham gia hoạt động này ví dụ như Hiệp hội BĐS, các công ty nhận ủy thác, các nhà đầu tư nước ngoài,...Đồng thời, nghiên cứu chính sách đưa các loại $\mathrm{CKH}$ BĐS vào niêm yết trên TTCK nhằm gia tăng tính thanh khoản cho các chứng khoán này, cũng như phát triển hành hóa trên TTCK.

(ii) Quản lý tốt thị trường tài chính: Kinh nghiệm của các nước và thực tế tại Việt Nam đã cho thấy, sự phát triển của thị trường $\mathrm{BĐS}$ phụ thuộc khá nhiều vào sự phát triển của thị trường tài chính. Khi thị trường $\mathrm{BĐS}$ bất ổn sẽ gây tổn hại không nhỏ cho thị trường tài chính và ngược lại, quản lý tốt thị trường tài chính sẽ giúp lành mạnh thị trường $\mathrm{BĐS.}$

(iii) Hình thành và phát triển các cơ quan quản lý, hỗ trợ: Để CKH BĐS thành công, chúng ta cần học tập kinh nghiệm của các quốc gia đã thành công trong phát triển hình thức huy động vốn này cho lĩnh vực BĐS như Nhật Bản, Hàn Quốc, Trung Quốc, cụ thể là thành lập các cơ quan chuyên biệt để quản lý hành chính và các tổ chức hỗ trợ (ví dụ như xếp hạng tín nhiệm các tổ chức BĐS có phát hành chứng khoán, kiểm soát minh bạch thông tin dự án, định giá các tài sản đảm bảo (BĐS) trước khi phát hành,....) nhằm đảm bảo quyền lợi cho nhà đầu tư khi mua các chứng 
khoán có nguồn gốc từ $\mathrm{BĐS.}$

(iv) Mở rộng phạm vi để các nhà đầu tư tham gia vào thị trường: Nguồn vốn từ các nhà đầu tư cá nhân trong nước có giới hạn, thường chỉ có thể tham gia vào những dự án nhỏ. Do đó, chính phủ cần có chính sách, qui định mở rộng phạm vi để các DN BĐS có thể phát hành chứng khoán thu hút các nhà đầu tư nước ngoài, các tổ chức tài chính lớn tham gia mua chứng khoán BĐS. Hoạt động kinh doanh BĐS là hoạt động có tính chất trung hạn, dài hạn, nhưng thực tế, chưa có cơ chế đầy đủ để tạo lập nguồn vốn đầu tư, nguồn vốn tín dụng trung hạn, dài hạn, vì thế, CKH BĐS nhằm thu hút vốn từ các nhà đầu tư dài hạn, nhất là nhà đầu tư nước ngoài là điều không thể thiếu. Tuy nhiên, nhiều qui định hiện nay đang hạn chế đối tượng này.

(v) DN BĐS cần minh bạch thông tin về các dự án BĐS có nhu cầu CKH BĐS, đặc biệt là đảm bảo tính chính xác và tin cậy của thông tin cung cấp cho nhà đầu tư, công chúng và các bên liên quan. Hiện tại, nhà đầu tư Việt Nam rất ngại vấn đề này vì nó mang lại rất nhiều rủi ro cho nhà đầu tư. Đồng thời, minh bạch thông tin, công bố đầy đủ các thông tin về pháp lý, qui hoạch, thời gian thực hiện của dự án, tiến độ,... không những tạo niềm tin để thu hút nhà đầu tư mà còn cũng cố lại niềm tin của nhà đầu tư, đảm bảo tính khả thi của quá trình thu hút vốn cho lĩnh vực BĐS, giảm bớt "sự e ngại", sự "không tin tưởng" của nhà đầu tư, củng cố uy tín, thương hiệu của DN BĐS.

(vi) CKH BĐS cần những nguồn nhân lực có kiến thức chuyên sâu về tài chính, am hiểu kỹ thuật chứng khoán và khả năng áp dụng trong bối cảnh CKH BĐS ở Việt Nam còn khá non trẻ. Hiện nay, nguồn nhân lực đáp ứng cho lĩnh vực này còn thiếu và yếu, vì thế cần đào tạo, bồi dưỡng.

Trong khuôn khổ bài viết này, có nhiều điểm chưa được đề cập đến như sự phát triển đồng bộ của thị trường tài chính và thị trường $\mathrm{BĐS}$, rào cản kỹ thuật, tâm lý và niềm tin... Bài viết này chỉ giới hạn trong khuôn khổ ý tưởng phát triển kênh huy động vốn mới cho ngành BĐS, vì thế, khi ứng dụng vấn đề này vào thực tế cần nghiên cứu sâu hơn theo đặc điểm và tình hình hiện tại

\section{Tài liệu tham khảo}

Barmat, J. (1990). Securization: An overview. In J. Lederman (Ed.), Handbook of asset-backed securities. New York, NY: New York Institute of finance.

Caselli, S., \& Gatti, S. (2005). Structured finance: Techniques, products and market. Germany: Springer Berlin - Heidelberg.

Davidson, A., Sanders, A., Wolff, L. L., \& Ching, A. (2003). Securitization: Structuring and investment analysis. Hoboken, $\mathrm{NJ}$ : Wiley.

Gambro, M. S., \& Leichtner, S. (1997). Selected legal issues affecting securitizatio. North Carolina Banking Institute, 1(1).

Hoang, C. V. (2016). Chưng khoán hóa vốn đầu tư bất động sản: Khả thi nhưng vẫn 'bi' [Real estate investment capitalization: Feasible but still 'secret']. Retrieved October 7, 2019, from Thời báo tài chính Việt Nam website: http://thoibaotaichinhvietnam.vn/pages/kinh-doanh/2016-0409/chung-khoan-hoa-von-dau-tu-bat-dong-san-kha-thi-nhung-van-bi-30540.aspx

Huyen Vu (2020). Súc khỏe của doanh nghiệp bất động sản [Real estate business health]. Retrieved October 8, 2019, from Vietstock website: https://vietstock.vn/2020/04/suc-khoe-cua-doanhnghiep-bat-dong-san-737-752412.htm

Le, L. T., Huyynh, H. T. C., \& Huynh, T. D. (2014). Chứng khoán hóa: Công cụ tài trợ cho bất động sản Việt Nam [Securitization: A sponsorship tool for real estate in Vietnam]. Tạp chí Phát 
triển và Hội nhập, 16(26).

Mirae Asset. (2020). Báo cáo thị trưòng trái phiếu [Bond market report]. Retrieved October 9, 2019, from https://masvn.com/api/attachment/file/1599806150744-Vietnam-C-bond_1Q20_vn.pdf

Ngân hàng nhà nước (NHNN). (2019). Thông tur số 22/2019/TT-NHNN ngày 15/11/2019 của Ngân hàng nhà nuớc Việt Nam về Quy định các giới hạn, tỷ lệ bảo đảm an toàn trong hoạt động của ngân hàng, chi nhánh ngân hàng nước ngoài [Circular 22/2019/TT-NHNN dated 15 November 2019 The State Bank of Vietnam on the Regulations on prudential ratios and limits in the operations of banks, foreign bank branches]. Retrieved October 20, 2019, from

https://thuvienphapluat.vn/van-ban/Tien-te-Ngan-hang/Thong-tu-22-2019-TT-NHNN-quydinh-gioi-han-ty-le-bao-dam-an-toan-trong-hoat-dong-cua-ngan-hang-411947.aspx

Ngo, T. T. P. (2017). Huy động vốn cho thị trường bất động sản thông qua chứng khoán hóa các khoản vay nợ ở Việt Nam [Raising capital for the real estate market through securitization of loans in Vietnam]. Tạp chí Kinh tế và Phát triển, 242.

Organization for Economic Cooperation and Development (OECD). (1995). Recommendation of the council of the OECD on improving the quality of government regulation. Retrieved October 15 , 2019, from https://www.oecd.org/officialdocuments/publicdisplaydocumentpdf/?doclanguage=en\&cote $=\mathrm{OCDE} / \mathrm{GD}(95) 95$

Pham, L. K. (2018). Chứng khoán hóa và nhũng bài học kinh nghiệm thưc tiễn tù̀ khủng khoảng thị truòng BĐS của Mỹ [Securitization and practical lessons learned from the US real estate market crisis]. Retrieved October 16, 2019, from Tạp chí tài chính doanh nghiệp website: https://taichinhdoanhnghiep.net.vn/chung-khoan-hoa-va-nhung-bai-hoc-kinh-nghiem-tukhung-hoang-thi-truong-bat-dong-san-my-d14871.html

Tạp chí Chứng khoán 6/2017 (2017). Chưng khoán hóa các khoản vay có thế chấp bất động sản: Con đường kết nối thị trường chứng khoán và thị trường bất động sản [Securitization of mortgage loans: A way to connect the stock market and the real estate market]. Retrieved October 6, 2019, from http://tapchitaichinh.vn/nghien-cuu--trao-doi/trao-doi-binh-luan/conduong-ket-noi-thi-truong-chung-khoan-va-thi-truong-bat-dong-san117239.html?mobile=true

Theurillat, T., \& Crevoisier, O. (2012). The sustainability of a financialized urban megaproject: The case of Sihlcity in Zurich. International Journal of Urban and Regional Research, 37(6), 2052-2073.

Theurillat, T., \& Crevoisier, O. (2013). Sustainability and the anchoring of capital: Negotiations surrounding two major urban projects in Switzerland. Regional Studies, 48(3), 501-515.

Thuy Linh (2019). Siết tín dụng - "Cú đấm” mạnh vào thị truoòng bất động sản [Credit tightening "A punch" is strong in the real estate market]. Retrieved October 17, 2019, from Báo Tài Nguyên và Môi Trường website: https://baotainguyenmoitruong.vn/siet-tin-dung-cu-dammanh-vao-thi-truong-bat-dong-san-296215.html

Truong, L. (2019). Tình hình vay nợ của các doanh nghiệp bất động sản niêm yết [The debt situation of listed real estate businesses]. Retrieved October 5, 2019, from https://cafef.vn/tinh-hinhvay-no-cua-cac-doanh-nghiep-bat-dong-san-niem-yet-20191203110203281.chn 